been found in the tissues, as the cornea, iris, and ciliary body, of seemingly unaffected eyes of syphilitic foetuses and babies by Peters, ${ }^{8}$ by Gierke and Stock, ${ }^{9}$ by Bab, ${ }^{10}$ by Schlimpert, ${ }^{11}$ and, lastly, by myself. ${ }^{12}$ These observations naturally raise the question whether the spirochætæ observed by me and described in the present communication would not have been found in the cornea of the patients apart from the existence of keratomalacia. With regard to this point I am prepared to express no opinion.

Welbeck-street, $W$.

\section{REVEALED TUBERCULOSIS IN CHILDREN AT SCHOOL AGES, FROM FOUR TO FIFTEEN YEARS. ${ }^{1}$}

BX H. C. LECKY, B.M. OXON., D.P.H., RESIDENT MEDICAL OFFICER, BOROUGH SANATORIUM, AND DEPUTY MEDICAL OFFICER OF HEALTH, BRIGHTON; AND

W. CLAUDE HORTON, M.B. BIRM.

LATE RESIDENT MEDICAL OFFICER, CHILDREN'S HOSPITAL, BRIGHTON.

AT the suggestion and request of Dr. A. Newsholme we have examined a number of school children for the purpose of determining the amount of revealed tuberculosis among them. It seems necessary to use the word "revealed" in order to prevent the drawing of incorrect conclusions. No physical examination will discover the small caseous, mediastinal, or retroperitoneal gland which is just as dangerous to the future of the child as an arrested patch of tuberculosis in the lungs. Again, a certain percentage of children show enlarged and obviously pathological glands in the neck. A carious tooth or a susceptible tonsil will allow many organisms to pass in and set up these changes. Until the gland caseates, or some other confirmatory change occurs, it is not justifiable to call it tuberculous. There is one test which we have not been able to make. If the taberculous opsonic index of each case could be taken on several occasions the diagnosis would in most cases be settled and a valuable amount of information would be obtained. The research would be long and tedious and not the least difficulty would be to obtain consent from the parents.

\section{The Class of Children Examined.}

For the purpose of this inquiry we examined different collections of children as follows :-

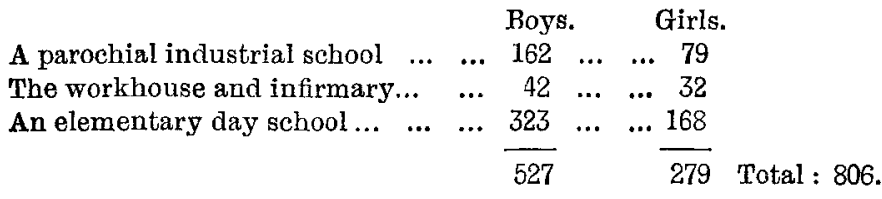

The children at the industrial school have every care and attention bestowed on them. They are sent direct from the workhouse and thereiore belong to the pauper classes. They are to a certain $\epsilon$ xtent a selected population. No child that is bedridden or requires constant medical supervision would be transferred to the school. Every child in a fit condition to be at school is sent. The children at the workhouse and infirmary are those who enter casually day by day and those who for various medical reasons are not fit to be sent to the industrial school. The examination of these two sets of children, within a few days of each other, affords in the aggregate an approximately accurate picture of an average sample of the institutionaliy treated pauper children at that time of year (May and June). The elementary school selected was an average example of a primary school. It must be remembered that the scholars in elementary day schools form a selected population, so far as most constitutional and some local diseases are concerned. The diseases discovered would be those giving rise to either negligible or no subjective or objective symptoms.

The three forms of taberculosis which one might expect to find previously unrtcognised are early pulmonary tuberculosis, tuberculous glands, and caries of the spine.

8 Klinisches Mondtsblatt fiir Augenheilkunde, August, 1906. 9 Ibid.

10 Deutsche Medicinische Wochenschrift, Nov, 29th, 1906. It Ibid.

12 Ophtha. moscope. June, 1907

1 A paper read bef, re the Second International Congress of School Hygiene, August, 1907.
In order to discover whether much tuberculosis capable of diagnosis exists among children, although it has either given rise to no symptoms or to symptoms which have been neglected, it is absolutely necessary to examine a large number of children. Such unrecognised tuberculosis in. adults is not infrequent, as is shown by our local experience in Brighton at the borough sanatorium.

\section{On what Evidence oan Tuberoulosis in Children be Diagnosed?}

The lungs.-The difficulty of diagnosing early pulmonary tuberculosis in children is very great. When a child begins to breathe deeply fine râles are frequently heard over the edges of the lungs. These signs rapidly disappear. Not. infrequently moist sounds are heard over other portions of the lungs at the beginning of an examination; these also, as a rule, disappear after several deep inspirations. Sometimes, at one or other base, or at both, fine inspiratory râles are heard, without any alteration of the breath sounds. The percussion note is not altered appreciably and vocal resonance is normal. These signs, we assume, are due to pleurisy, and there is generally no evidence that the pleurisy is tuberculous. If as a result of tuberculosis the lung tissue is sufficiently changed to produce moist sounds, then changes in the breath sounds in vocal resonance and possibly in percussion note would also be present, but the persistence of râles at one apex on and after coughing, and also after numerous deep inspirations, we should consider good evidence of pulmonary tuberculosis. In some cases rhonchi are present with or without a cough. These we have attributed to a passing bronchitis.

The abdomen. - The examination of the abdomen in a child, unless there is ample time, is very unsatisfactory. Especially is this the case if there is no bed or comfortable couch at hand. We examined the abdomens of the first 300 cases. At the elementary schools, however, this examination was stopped partly from lack of convenience and partly from lack of time sufficient to make the results trustworthy. Probably the subjective signs of tuberculous peritonitis occur early, and it is not likely that we have missed cases of revealed tuberculosis from neglecting this part of the examination.

Bones.-Caries of the spine is the only form of bone tuberculosis which one would expect to have remained previously undiscovered. The subjective signs of disease of the long and short bones are evident early, and the child would not attend school many days without some notice being taken either by the parents or teachers.

Joints.-For similar reasons one does not expect to find evidence of early joint diseases in school children. If joint or bone disease be discovered it will probably be old and now arrested, except in the case of caries of the spine.

Glands.-It is very exceptional, in our experience, to meet a child without palpable glands in the neck. In the majority of cases they are at once felt without the slightest diffi. culty. The best way is to stand behind the child and at the same time to palpate each side of the neck with the corresponding hand. The glands most readily felt are either the most posterior of the submaxillary group or the upper part of the deep cervical group. The superficial cervical are less frequently felt. If other glands in the neck are enlarged some local sore is usually found in connexion with them. We cannot speak so decidedly about the other glands in the body as we have not examined them systematically. The difficulty is to state what size of glands is normal for children and what degree of largeness and hardness must be reached before tuherculosis can be diagnosed. That bad teeth and tonsils form ready channels of infection for many germs there is no doubt, and the great majority of children in elementary schools are known to have carious teeth. Although stating size by comparing with natural objects is unsatisfactory, it is a better classification than none at all. We have adopted the following scheme:-

$\begin{array}{ccccccccc}\text { Glands, readily felt (almonds) } & \ldots & \ldots & \ldots & \ldots & \ldots & 1 \\ ,, \quad, \text {, size of filberts } & \ldots & \ldots & \ldots & \ldots & \ldots & \ldots & \ldots & 2\end{array}$

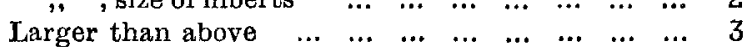

Intermediate stages between the above we ciescribe by adding the sign plus $(t)$ or minus $(-)$ after the numeral.

We look upon children whose glands are 3 as being cases suspicious of tuberculosis, unless some other obvious cause is at hand. Bad teeth only indicate the channel of infection and not the specific infection itself. When thickened scars or old sinuses occur in connexion with glands we consider 
the case to be tuberculous unless there is a history of a concomitant acute infectious disease.

Other forms of tuberculosis.- Lupus of the face or conditions simulating it are readily seen, but the diagnosis is at times difficult. We did not examine for tuberculosis of the testes. Tuberculous meningitis, being nearly always acute or subacute in its onset, no child suffering from it could attend school many days without showing signs of ill-health.

\section{Method of Examination.}

In every case the child was stripped to the waist. The general nutrition was noted and roughly stated as good, fair, or bad. The child was asked about a cough and discharge from the ear. The answers were, as a rule, so undecided that it is doubtful whether the questions were not a waste of time. The glands of the neck were carefully examined, Any local sores, the condition of the teeth, and the state of the scalp were noted to help to explain any enlargement of the cervical glands that might be present. The heart and the lungs were auscultated, the other aids to diagnosis being only employed when any adventitious sounds were heard. We nsed to percuss the chest when we began our inquiry, bat it is very improbable that if the chest is inspected carefully and each of the five lobes auscultated, any disease would be missed in this way that would not also be missed if the chest were examined in the routine manner. The hands were looked at (for dactylitis, \&c.), the limbs palpated, and the joints passively flexed. At the same time the child was asked whether he had ever had anything the matter with his arms or legs. The result of each part of the examina tion was entered on the following schedule, and the summary of the evidence as to the presence of taberculosis was at once written down as positive, negative, or doubtful.

Schedule.

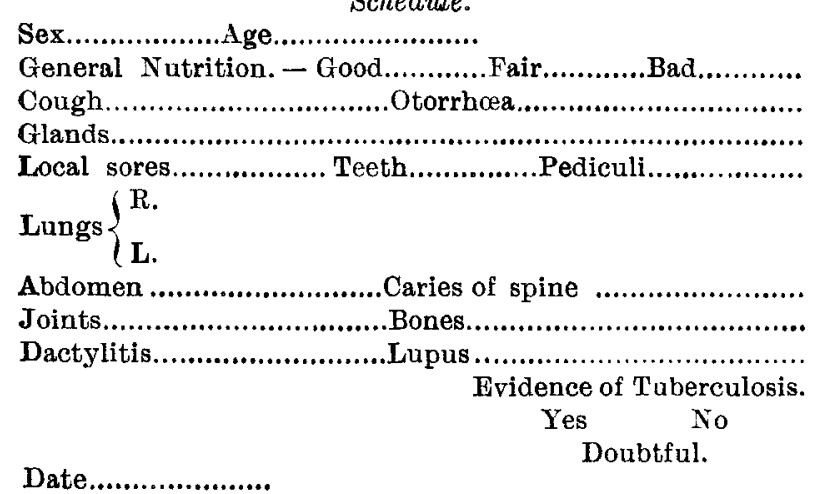

Results of the Examination of 806 Children at School Ages in Brighton.

In the following table we give the summary of our work :-

TABLE I.-Summary of Examination of 806 Sohool Children in Age Groups.

\begin{tabular}{|c|c|c|c|c|c|c|c|c|}
\hline$\underset{\text { (years). }}{\text { Ages }}$ & 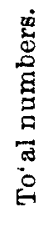 & 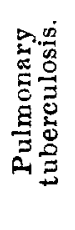 & 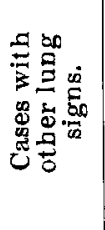 & 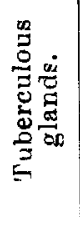 & 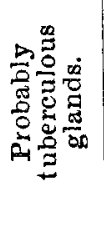 & 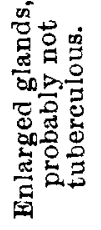 & 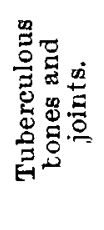 & 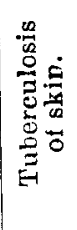 \\
\hline $4-5$ & 48 & 0 & 3 & 0 & 0 & 8 & 0 & 0 \\
\hline $5-6$ & 53 & 0 & 5 & 0 & 1 & 5 & 0 & 0 \\
\hline $6-7$ & 59 & 0 & 3 & 0 & 3 & 21 & 0 & 0 \\
\hline $7-8$ & 81 & 0 & 11 & 2 & 0 & 21 & 0 & 0 \\
\hline $8-9$ & 77 & 0 & 5 & 1 & 0 & 14 & 1 & 0 \\
\hline 9-10 & 81 & 0 & 6 & $I$ & 1 & 15 & 1 & 0 \\
\hline $10-11$ & 88 & 2 & 2 & 2 & 1 & 26 & 0 & 0 \\
\hline $11-12$ & 83 & 0 & 1 & 0 & 0 & 14 & 0 & 0 \\
\hline $12-13$ & 89 & 0 & 2 & 1 & 0 & 22 & 0 & 0 \\
\hline $13-14$ & 77 & 1 & 1 & 0 & 0 & 16 & 2 & 1 \\
\hline $14-15$ & 47 & 0 & 1 & 0 & 0 & 10 & 2 & 2 \\
\hline $15-17$ & 23 & 0 & 0 & 0 & 0 & 7 & 1 & 0 \\
\hline Total... & 806 & 3 & $40^{\circ}$ & 7 & 6 & 169 & 7 & 3 \\
\hline \multicolumn{2}{|c|}{ Per cent. } & 0.37 & $4 \cdot 96$ & 087 & 0.74 & 2096 & 0.87 & 0.37 \\
\hline
\end{tabular}

We give here in detail the evidence on which we diagnosed the three cases of pulmonary tuberculosis.

CASE 1.-The patient was a boy, aged ten years (at the parochial industrial school). Rhonchi were heard all over the right side. On the left there was diminished movement with fine inspiratory râles at the base, both in front and behind. In addition he had a scar over the right ankle adherent to the bone. This boy was afterwards treated in the Brighton Borough Sanatorium. He was made to expectorate with some difficulty and tubercle bacilli were subsequently found in the sputum.

CASE 2.- The patient was a boy, aged ten years (an inmate of the infirmary). He looked ill and thin and was poorly nourished. He was subject to cough. He was recovering from a three weeks' illness of intermittently high temperature. There were signs of thickened pleura over the lower half of the left lung. He had previously been diagnosed as a case of pulmonary tuberculosis and his mother died from that disease about a year ago. The boy had been treated before for similar attacks of pyrexia and pain in the side.

CASE 3.-The patient was a boy, aged 13 years (at an elementary day-school). His general nutrition was not good. The glands in the neck were larger and firmer than normal. At the right apex posteriorly and also over the right clavicle moist râles could be heard on deep inspiration wbich persisted after coughing. An occasional rhonchus was heard at the right base.

The children with other lung signs were mainly cases of bronchitis. In six of the seven cases in which we diagnosed tuberculous glands of the neck, scars were also present in addition to the enlarged hard glands. In the seventh case the size and consistence of the glands left no room for doubt. The cases of tuberculous bones and joints were all quiescent and we met none in which the sinus was still discharging. The two cases of lupus were both in children. aged 14 years. Neither case was, nor had been, under treatment for this particular affection. The boy had a small patch of lupus on the right wrist and a discharging sinus from the epicondylar gland of the same side. The girl had a scar in connexion with the submental gland, and Dr. Williams, who very kindly examine $\lambda$ the case for us, said there was no doubt the skin had become secondarily infected with tubercle bacilli. One case of tuberculous onychia was found which had been under treatment for some years. We examined the abdomen in the first 300 cases and in only one did we find any evidence suggesting tuberculous peritonitis. For the reasons stated above this examination was abandoned.

Comparison with the Results of Others.

Table II. states our results as a whole and compares them with those obtained by others. The examinations conducted in Scotland were not undertaken with the express purpose of investigating tuberculosis in children. But in every case the examination was of sufficient scope to make the results comparable with ours.

Although each series of figures is scanty, when the results are compared, it is clear that the observers vary to a very large degree as to what can be called pulmonary tuberculosis and what is only sufficient ground for suspecting it. In Edinburgh, out of 600 cases, 14 were diagnosed positively as pulmonary tuberculosis; in Brighton we are only certain of 3 out of 806 ; and in Aberdeen 3 out of 600 were thought probably to be of the same nature. Similar dis. crepancies appear in the column of other lung signs. But as bronchitis figures most largely here, the time of the year at which the examination was made may account for some of the differences. With regard to the glands, it is obvious there is no common ground for the various observers. In Dunfermline the glands were not palpable in nearly 40 per cent. In Brighton we have not found a single case in which we could not feel one or other gland in the neck. Children with excellent teeth, with clean heads, with no sores on the face or neck, and apparently with normal throats, may still have glands that we should class as $1+$ or $2-$. The condi. tion of the teeth among the school children is exceedingly bad. The vast majority have one or more carious teeth. If the teeth form the most important channel for miscellaneous infection of the neck glands the explanation of the very large number of abnormally enlarged glands which we found is at hand.

Collateral Evidenoe of Tuberculosis in Scholars.

Further evidence as to the amount of tuberculosis among school children can be obtained from $(a)$ the number of 
Table II.-Comparative Regults Obtained in Examining School Children, stately as Percentages.

Place, authority, and year.

Dundee, Dr. A. P. Low (Report of Investigation into Social Conditions in Dundee), 1905.

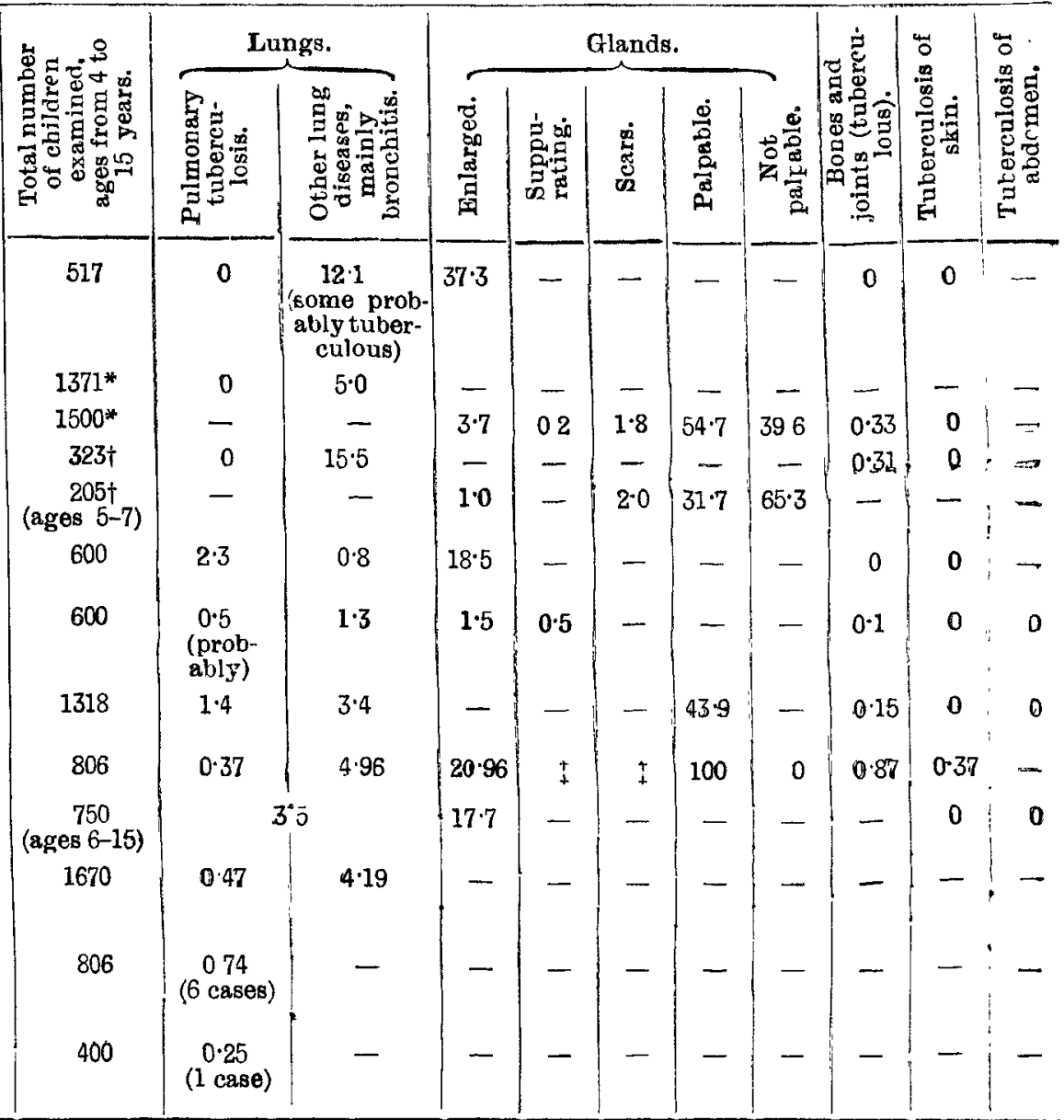

Dunfermline, Dr. R. V. C. Ash (First Annual Report on the Medical Inspection of School Children in Dunfermline), 1906.

Edinburgh, Dr. W. M. Mackenzie (Report of the Royal l Commission on Physical Training (Scotland)), 1903.

Aberdeen, Professor M. Hay (Report of the Royal Commission on Physical Training (Scotland)), 1903.

Edinburgh (Cannongate School), (Edinburgh Charity Organisation Society), 1906.

Brighton, Dr. W. C. Horton and Dr. H. C. Lecky, 1907

Glasgow, Dr. A. H. Edwards (Journal of the Royal Sanitary Institute, vol. iii., part 4, p. 914), 1904.

$\$$ London, Dr. J. F. Squire and Miss A. Gowdey (paper read before the Second International Congress of School Hygiene), 1907.

$\$$ Leith, Dr. W. Robertson and several practitioners (British Journal of Tuberculosis, July, 1907, p. 229) 1906.

Blackburn, Dr. A. Greenwood (British Journal of Tuberculosis, July, 1907, p. 228), 1906 or 1907.

A dash (-) implies that no observations under this heading were recorded; 0 implies negative observations.

The numbers given in these two lines relate to the same group of children.

$\uparrow$ The numbers given in these two lines relate to the same group of children. 0.87 per cent. of the Brighton children had tubereulous glands and 0.74 per cent. probably had tuberculous glands, in addition
to the 20.96 per cent. of enlarged glands.

These results have been added since this paper was read.

notified cases of pulmonary tuberculosis, and $(b)$ the number of deaths from all forms of tuberculosis among school children, both being stated in proportion to the population at school ages; $(c)$ the certified medical causes of nonattendance at school ; and $(d)$ the causes leading children to be refused admission to school when they have reached school age. Under the first two headings the following local information is available.

TABLW III.-Brighton.-Tuberculosis Cases, Deaths, and Annual Rates per 100,000 of Population at Stated Age Periods (Based on the Experienoe of the Three Years 1904-06).

\begin{tabular}{|c|c|c|c|c|c|c|}
\hline \multirow[b]{2}{*}{ Age periods. } & \multicolumn{2}{|c|}{$\begin{array}{l}\text { Cases of pul- } \\
\text { monary tubercu- } \\
\text { losis notified. }\end{array}$} & \multicolumn{2}{|c|}{$\begin{array}{l}\text { Deaths from } \\
\text { pulmonary } \\
\text { tuberculosis. }\end{array}$} & \multicolumn{2}{|c|}{$\begin{array}{l}\text { Deaths from other } \\
\text { forms of } \\
\text { tuberculosis. }\end{array}$} \\
\hline & 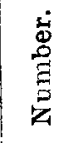 & 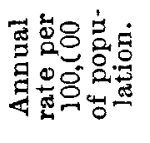 & 总 & 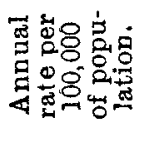 & 这 & 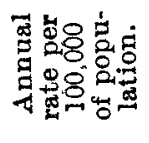 \\
\hline $0-4$ & 23 & 79 & 18 & 62 & 117 & 402 \\
\hline $4-15$ & 148 & 190 & 13 & 17 & 46 & 59 \\
\hline 15 and over. & 889 & 324 & 500 & 182 & 66 & 24 \\
\hline
\end{tabular}

$(a)$ and $(b)$. It is seen from the figures in Table III. that while 190 children per 100,000 of the population at the ageperiod 4-15 years are annually notified to be suffering from pulmonary tuberculosis, only 17 die from that cause. Assuming the notifications to be correct ${ }^{2}$ the explanation is that the children either become chronic invalids or that the disease becomes arrested. Experience negatives the former conclusion-e.g., of 1265 out-patients attending the Children's Hospital, Brighton, between January and June, 1907, only

2 This point is mentioned, because a certain proportion of the children notified to be suffering from pulmonary tuberculosis were admitted to the sanatorium with their phthisical parents and some six were diagnosed as pulmonary tuberculosis. We must therefore adopt the latter view. The number of notified cases amounts to about 0.2 per cent. of the population at school ages (190 in 100,000) while the actual proportion which we found in our special examinations of scholars (Table I.) was 0.4 per cent. This percentage, it should be added, is based on three cases found in 806 children.

$(e)$. The only analyses of the causes of non-attendance at school that we have been able to obtain are those published by Dr. A. Greenwood, medical officer of health of Blackburn. The results, as they relate to tuberculosis, are given in percentages below. The percentages are derived trom the examination of children, specially referred to Dr. Greenwood by the school attendance officers as to their fitness for school, concerning whom doubt as to health had already been entertained.

TABLE IV.-Blaokburn.

\begin{tabular}{c|c|c|c|c}
\hline Date. & $\begin{array}{c}\text { Number of } \\
\text { children ex- } \\
\text { amined stated } \\
\text { as 100 (actual } \\
\text { numbers in } \\
\text { brackets). }\end{array}$ & $\begin{array}{c}\text { Number of } \\
\text { cases of } \\
\text { pulmonary } \\
\text { tuberculosis } \\
\text { found } \\
\text { (per cent.). }\end{array}$ & $\begin{array}{c}\text { Number of } \\
\text { cases found } \\
\text { of other } \\
\text { forms of } \\
\text { tuberculosis } \\
\text { (per cent.). }\end{array}$ & $\begin{array}{c}\text { Total } \\
\text { number of } \\
\text { tuberculous } \\
\text { cases (per } \\
\text { cent.). }\end{array}$ \\
\hline $\begin{array}{c}\text { Oct., 1903- } \\
\text { Dec., 1904 } \\
\text { Jan., 1905- } \\
\text { Dec., 1905 } \\
\text { Jan., 1906- } \\
\text { Dec., 1906 }\end{array}$ & $100(338)$ & 100 & 60 & $16 \cdot 0$ \\
\hline Total _... & $100(338)$ & 50 & $1 \cdot 8$ & $6 \cdot 8$ \\
\hline $100(1028)$ & $6 \cdot 7$ & $7 \cdot 4$ & 12.5 \\
\hline
\end{tabular}

Dr. Greenwood's figures are important. Of 1028 chiliste who appeared to be unfit for school he found that 67 per cent. were suffering from pulmonary tuberculosis. Taking this high percentage in conjunction with the low percentages in the series in Table II. it follows that a child failing with pulmonary tuberculosis becomes ill very quickly and does 
not remain long in school before his ill-health is recognised. Such patients evidently do not play any considerable part in spreading this disease among school children.

(d) Dr. Mackenzie, in his book on the "Medical Inspection of School Children," gives two references to the School Report of the Town of Zürich. In 1899, of 2625 children who had reached the age for school attendance, only 145 were rejected on medical grounds. In 1892, of 2994 children 142 were rejected. The cause of each rejection is given, and in no case is any form of tuberculosis mentioned. 'The age for commencing school at Zürich is "at the beginning of the school year subsequent to the attainment at the child's sixth birthday." Here again is confirmatory evidence that there is very little revealed tuberculosis among children sent to the elementary schools.

\section{Conclusions.}

1. The amount of revealed pulmonary tuberculosis among school children is very small. We found three cases in 806 children. This is supported by the results at Dundee, Aberdeen, and London. The figures of pulmonary taberculosis among school children at Edinburgh are so large as to need further examination.

2. The extremely small percentage of cases of pulmonary tuberculosis found among unselected school children in every centre investigated except Edinburgh and the total absence of refusals to allow school attendance in Zürich on account of tuberculosis, as contrasted with the relatively large percentage of cases of pulmonary tuberculosis found among school children specially referred to a medical man owing to a suspicion of, or evident, ill-health indicate that when pulmonary tuberculosis does start in children they quickly show it by failing health and are removed from school. The schools cannot, therefore, be considered as places where much tuberculosis is spread. (The question of tuberculosis among the teachers is not here considered, the subject falling outside the scope of the paper.)

We are much indebted to Dr. Newsholme for great kindness and help throughout this investigation.

\section{OBSERVATIONS ON CASES OF STREPTO- COCCAL MENINGITIS.}

\section{BY W. JAMES WILSON, B.A., M.D. R.U.I., D.P.H. CantTab. \\ (From the Musgrave Pathological Laboratory, Queen's College, Belfast.)}

AT present much attention is being given to the subject of epidemic cerebro-spinal meningitis and difference of opinion exists as to the route by which the meningococcus reaches the meninges. The old view and one which is still widely held is that the meningococcus from its primary seat in the rasopharynx extends up to the base of the brain along the lymphatics; the other view is that in cerebro-spinal fever we have a general infection, the meninges being infected from the blood. The discovery of the meningococcus in the blood by Elser, ${ }^{1}$ Andrewes, ${ }^{2}$ Symmers and Wilson, ${ }^{3}$ Simon, ${ }^{4}$ Birnie and Smith, ${ }^{5}$ and the characteristic abdominal lesions ${ }^{6}$ lend support to the latter view. Andrewes's case is specially interesting as being one of septicæmia due to the meningococcus without any inflammation of the meninges being present. How the meningococcus enters the blood, whether from the nasopharynx or from the intestine, is still undecided. It appeared to me that the character of the streptococci occurring in cases of streptococcal meningitis might by analogy throw some light on the problem.

The researches of Gordon ${ }^{7}$ and Andrewes and Horder"show that streptococci according to their fermentative powers can

1 Elser: Journal of Medical Research, 1905, vol, xiv.. No. 1. 2 Andrewes : THE LANCET, April 28th, 1906. p. 1172

4 Simon: Journal of the American Medical Association, June 8th, 1907.

5 Birnie and Smith: The American Journal of the Medical Sciences, October, 1907

${ }^{6}$ Symmers : Brit. Med. Jour., Feb. 16th, 1907. 7 M. H. Gordon : Local Government Board Medical Reports, 1902-3,
1903-4; THE LANCET, Nov. 11th, 1905, p. 1400.

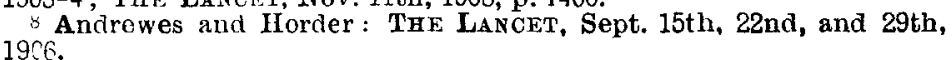

be divided into seven classes-namely, streptococcus equinus, streptococcus mitis, streptococcus pyogenes, streptococcus salivarius, streptococcus anginosus, streptococcus fæcalis, and pneumococci. Streptococci of the salivarius and troalis classes are found in the saliva and fæces respectively. However, streptococci of the salivarius class are also present in the fæces, but streptococci of the fæcalis class have never been found in the saliva. The reaction on which the above observers rely in distinguishing a streptococcus salivarius from a streptococcus fæcalis is the power to terment mannite possessed by the latter. Gordon examined 300 streptococci isolated from normal saliva and failed to find a mannite fermenter among them. The above classification is, of course, only a provisional one, and further research may show that the characters on which it is based are not con. stant. Not forgetful of this limitation we may ask, In cases of streptococcal meningitis is it the organism peculiar to the saliva or that peculiar to the fæces that is present?

I have recently had the opportunity of examining the lumbar puncture fluid of five cases of streptococcal meningitis. In two of these, however, the death of the cocci prevented me from fully investigating their fermentative powers; one of them produced acid in litmus broth containing 1 per cent. of lactose, saccharose, and salicin respectively, but as it did not ferment mannite it probably did not belong to the fæcalis group; the other was probably a pneumococcus. The fermentative powers of the remaining three can be seen in Tables I. and II., and for comparison I have included the changes produced on the same substances by streptococci of the salivarius and frealis classes kindly given to me by Dr. T. J. Horder and by a typical "rheumococcus" obtained originally from Dr. J. M. Beattie. The + signifies acid production.

TABLE I.

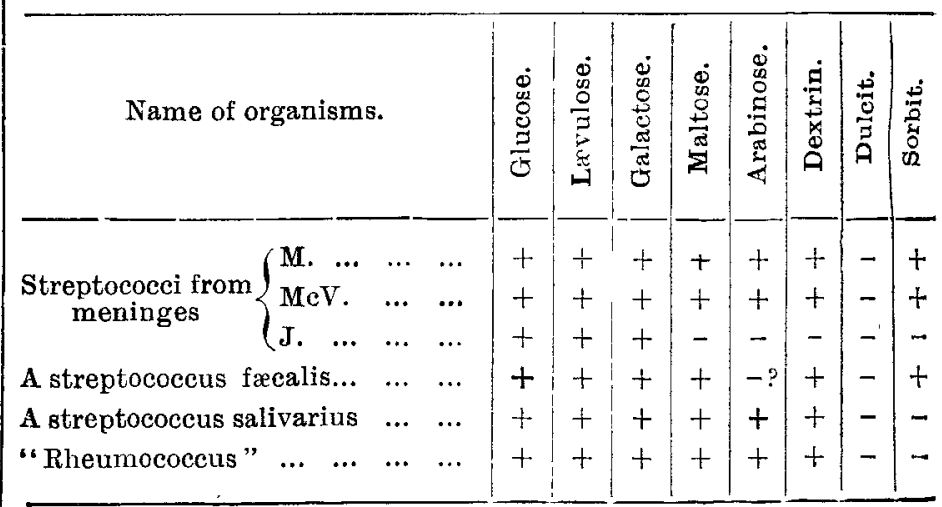

TABLE II.-Reactions with Gordon's Nine Tests.

\begin{tabular}{|c|c|c|c|c|c|c|c|c|c|c|}
\hline Name of organisms. & $\overbrace{\frac{\mathbf{L i t}}{\mathrm{mi}}}^{\mathbf{\mathrm { Li }}}$ & 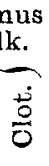 & 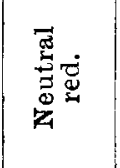 & 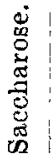 & 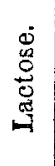 & 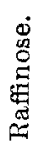 & $\underset{\Xi}{\stackrel{\Xi}{\Xi}}$ & 胥 & 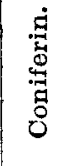 & 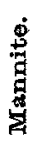 \\
\hline $\begin{array}{c}\text { Strepto- } \\
\text { cocci }\end{array}$ & + & + & $\begin{array}{r}\text { FIuor- } \\
\text { escence. }\end{array}$ & + & + & - & - & + & $\begin{array}{c}\text { Not } \\
\text { tried. }\end{array}$ & $t$ \\
\hline from $\{\mathrm{McV}$. & + & $t$ & None. & + & + & + & - & + & - & + \\
\hline meninges. (J. $\ldots$ & + & - & , & + & + & + & - & - & . & + \\
\hline $\begin{array}{c}\text { A streptococcus } \\
\text { frecalis ... } \\
\text {... }\end{array}$ & + & + & $"$ & + & + & - & - & + & - & $t$ \\
\hline $\begin{array}{c}\text { A streptococcus } \\
\text { salivarius } \\
. .\end{array}$ & + & + & " & + & + & + & - & + & - & $m$ \\
\hline "Rheumococcus." & + & - & $"$ & + & + & - & - & + & • & $t$ \\
\hline
\end{tabular}

It is evident from the above tables that two of the organisms (M. and $\mathrm{McV}$.) belong to the fæcalis group. The third organism (J.) had much less fermentative power. It fermented mannite, though slowly, so that possibly it is more closely allied to the frealis than to the salivarins group. The growth of this organism (J.) on agar was thick and moist, quite different from ordinary streptococci and somewhat like that of the meningococcus but more opaque. Its vitality was good as it survived several weeks without subculture. Morphologically it showed large Gram-positive diplococci resembling in size and shape the giant forms occurring in cultures of the meningococcus. These results indicate that in a considerable proportion of cases the infecting organism comes from the intestine. 